\title{
Networks of Care among Families with Internationally Adopted Children in Spain*
}

\author{
Jorge Grau Rebollo \\ José Luis Molina González \\ Universitat Autònoma de Barcelona. Departament d'Antropologia Social i Cultural \\ jordi.grau@uab.cat \\ ORCID: 0000-0003-2709-8696 \\ joseluis.molina@uab.cat \\ ORCID: 0000-0002-2932-2690
}

Recepción: 03-05-2018

Aceptación: 06-09-2018

Publicación: 04-12-2018

\begin{abstract}
This study examines the relevance of informal support networks in adoptive parenting ("networks of care"). We try to go beyond the potential difficulties and specific stressors involved in International Adoption (IA) processes and the relevance of the interaction of both formal and informal support networks, since the role of informal personal grids in adoptive care has not been developed in depth so far. Hence, in order to identify the main factors that help determine the size, density, and effectiveness of support networks in everyday child care, we collected both qualitative and quantitative data from 50 adoptive families selected from a previous online survey $(n=477)$. Considering the distribution of responsibilities over children, the preferred information sources, and levels of concern among interviewees, we were able to group patterns of similarities in three clusters or profiles, which may help to better understand care practices among adoptive parents within ordinary situations. In this light, the data analysis shows that larger and denser networks do not necessarily mean better support. Rather, other factors such as the strength and duration of the adoptive project lead to more effective grids of care providers. We contend that an adequate knowledge of such configurations may be used by professionals and policymakers to facilitate proactive interventions in potentially vulnerable scenarios.
\end{abstract}

Keywords: Child care issues; family; adoption; parenting \& parenthood; social support networks

* This article is the result of the research project Parentescos: Formas de Parentalidad y Articulaciones Disciplinarias [Kinships: Forms of Parenthood and Disciplinary Articulations] (CSO2012-39041-C02-01), funded by the Spanish Ministry of Education, Culture and Sport. The authors wish to thank Dr. Julia Vich Bertran and Lourdes García Tugas for their invaluable help during the research. We also want to express our profound gratitude for the kind collaboration of all the parents who have participated in this research. 
Resumen. Redes de cuidado entre familias con menores adoptados por vía internacional en España

Este estudio examina la relevancia de las redes informales de apoyo en la crianza adoptiva («redes de cuidado»). Pretendemos con ello ir más allá de las dificultades potenciales y los factores estresantes específicos implicados en los procesos de adopción internacional (AI) y de la interacción entre las redes de apoyo formales e informales, ya que el papel de las redes personales informales en la atención adoptiva no ha sido, hasta el momento, suficientemente desarrollado. Así, para identificar los principales factores que ayudan a determinar el tamaño, la densidad y la efectividad de las redes de apoyo en el cuidado infantil cotidiano, hemos recopilado datos cualitativos y cuantitativos de cincuenta familias adoptivas, seleccionadas a partir de una encuesta en línea previa $(n=477)$. Teniendo en cuenta la distribución de responsabilidades sobre los niños, las fuentes preferidas de información y los niveles apreciables de preocupación entre las personas entrevistadas, encontramos ciertos patrones de similitudes clasificados en tres grandes grupos, los cuales pueden ayudar a comprender mejor las prácticas de cuidado entre padres adoptivos en situaciones cotidianas. En este sentido, el análisis de estos datos pone de relieve que disponer de redes más grandes y densas no necesariamente implica tener mejor apoyo. Por el contrario, otros factores como la fuerza y la duración del proyecto adoptivo conducen a redes más efectivas de proveedores de cuidados. El conocimiento de estas configuraciones reticulares puede ser de gran utilidad a profesionales y legisladores a la hora de facilitar intervenciones proactivas en escenarios potencialmente vulnerables.

Palabras clave: cuidado infantil; familia; adopción; crianza y paternidad; redes de apoyo social

\section{Summary}

$\begin{aligned} \text { 1. Introduction } & \text { 5. Conclusion and limitations } \\ \text { 2. Methods } & \text { 6. Implications for policymaking } \\ \text { 3. Results } & \text { and professional practice } \\ \text { 4. Discussion } & \text { Bibliographic references }\end{aligned}$

\section{Introduction}

The meteoric rise of international adoption (IA) in Spain, which increased from a low of 1,487 adoptees in 1998 to a peak of 5,541 in 2004, drew academic attention to the phenomenon and put international adoption programs on the political and media agendas. Despite a sharp decline over the following years, IA has remained firmly etched on the collective imagination. Although international adoptees account for only a small fraction of the total out-ofhome care in Spain, the impact of this form of child adscription has generated wide social debate and opened up new theoretical scenarios for a wide range of interrelated topics, such as exclusion, migration, identity, and the very notions of kinship and citizenship (Grau Rebollo, 2011; Howell \& Melhuus, 2009; Seligmann, 2006; Howell, 2006). Such a significant change in child-rearing profiles has also had several implications for practice and policymaking at the health, educational, and family levels. Consequently, most research is (and has 
been) directed toward problematic environments and high-risk scenarios in which families and adoptees' caregivers must cope with powerful stressors while developing resilience strategies (Henry et al., 2015). Increasing our knowledge of family settings that involve some degree of trauma is undeniably relevant. However, we believe that it is in ordinary, non-problematic child-rearing circumstances that the configuration of actual support networks may be identified (as no specific stressors trigger the need to search for specific resources). Insights into such common configurations in different adoptive parent profiles may be used by professionals and policymakers to facilitate proactive interventions when faced with rapidly developing situations of vulnerability.

Hence, our aim in this article is to shed light on the relevance of support networks in adoptive parenting by analyzing the effective configuration of informal networks in everyday care. In this analysis, we will focus on the essential and practical aspects of child-rearing and care in situations that are not directly constrained by the needs arising during the adoption process or by other high-risk stressors. In so doing, we mean to go beyond a "whodoes-what" perspective or the mere enumeration of parenting roles and their distribution among adoptive families. Instead, we propose to address the interconnection of the different agents involved in each case, thereby looking for regularities and differences as well as the implications of all these circumstances in child-raising. Thus, while the potential difficulties and specific stressors involved in IA processes have often been outlined (see, for example, Palacios \& Brodzinsky, 2010; Pudrovska, 2008) (see, for example, Palacios \& Brodzinsky, 2010; Pudrovska, 2008, and the relevance of support networks have frequently been highlighted (Bryan et al., 2010; Goldberg \& Smith, 2008; Hoffman, 2014; Kramer \& Houston, 1998), the particular role of informal networks within the adoptive family environment has not been addressed so frequently. Certainly, Lansford et al. (2001: 850) identified a significant gap in this regard nearly fifteen years ago and stressed the need to investigate connections between family processes, along with the quality of relationships and well-being within and across family structures. Following their suggestions, our aim is to look deeper into family structure by improving our knowledge of the network relationships that are consciously woven around child-rearing practices, regardless of the age, sex, or family status of each specific provider.

In order to accomplish this goal, we have taken a "personal networks" approach (Wellman, 2007). This approach has allowed us to elicit the specific configuration of interconnected care providers available for the selected person or Ego (in this case, the adoptive parent interviewed). In this respect, several studies have dealt with the relevance of support groups (either formal structures or informal assistance aggregates) at different levels and with different targets, such as peer mentoring (Bryan et al., 2010), birth parents (Claridge, 2014), family networks among gay and lesbian adoptive parents (Erich et al., 2005), social support in pre-adoptive couples (Goldberg \& Smith, 2008), families adopting children with special needs (Kramer \& Houston, 1998), post-adoption contact (Neil, 2007b) and open adoption (Miall \& March, 
2005). Thus, we take a step further in the relevant field of subjective perceptions of well-being (Denuwelaere \& Bracke, 2007) to analyze the effective role of personal networks in well-being.

In our research, all interviewees acknowledged social support as a strategic constituent of coping with vulnerability in everyday life. Furthermore, several studies have found that the mere perception of the availability of social support may be as important as the actual support received (Mcgrath et al., 2014). Such support may originate in formal (institutional) or informal (personal contacts) sources, and cover various day-to-day aspects of care both in post-adoption contexts (practical assistance, emotional support or advice, and recognition; see Cutrona, 2000) and during the pre-adoptive period (emotional support, informational assistance, and specific aid; see Groza, 1996).

The role of personal networks as sources of social support has also been widely discussed (Bidart \& Lavenu, 2005; Wellman \& Wortley, 1990). In this article, we address some questions which are fundamental to this line of enquiry: (a) Are there different types of care networks in the field of international adoption, from the viewpoint of adoptive parents? If so, (b) are those types of support networks related to the strength and coherence of the associated adoptive project?

In order to address these questions, the remainder of the article is organized as follows: First we will describe the methods used, including the personal network data; we will then present the results, paying attention to specific qualitative case studies which we believe to best exemplify the overall findings. In the following section, we will discuss the results and reflect upon the significance and limitations of our study. Finally, we will discuss some implications for policymaking and professional activity.

\section{Methods}

\subsection{Procedures and data collection}

In order to begin the analysis of ego-centered support networks, we followed a three-step recruitment process. Firstly, we recruited 477 adoptive parents from different adoptive family associations and administered an online questionnaire to them, enabling us to gather a wide range of information which has been analyzed elsewhere (Grau Rebollo et al., 2016; Grau Rebollo et al., 2014). This phase gave us a broad overview of certain issues and - most central to our purpose here - provided participants for further stages. We included a request for an in-depth interview in the questionnaire and sent a letter to those adoptive parents willing to participate, inviting them to contact the investigators by telephone or e-mail. Of the candidates who responded, 61 were selected to proceed with an in-depth interview based on the following selection criteria: (1) participants' availability, (2) diversity in terms of age and marital status, (3) diversity of sociodemographic profiles, and (4) participants' willingness to participate in a second interview aimed at providing greater detail with a specific network analysis. 
These interviews were useful to qualitatively broaden and develop some topics that could only be outlined in the initial questionnaire. Several sets of questions were included to collect data on:

(1) the participant's sociodemographic and adoptive profiles;

(2) the distribution of practical childcare tasks;

(3) their main providers of support;

(4) The adoptive parent's concerns about the child's physical and cognitive development, the influence - if any — of the adoptee's origins, and his/her social adaptation and adjustment to the family, and

(5) the adoptive parent's expectations and fears about possible future problems for the child, due to his/her condition of adoptee.

We interviewed one person per family and appointments were made at the participant's convenience, either face-to-face, over the phone, or via Skype. Lastly, we arrived at a final sample of 50 interviewees who were willing to provide detailed information on their personal networks. This third data-gathering technique would help us to identify possible patterns in support-seeking needs among adoptive families. In order to elicit such information, we prompted them to nominate those people whom our informant (hereafter referred to as "Ego"; i.e., Mccarty \& Molina, 2014) considered of upmost importance and gathered data on the sex, age, and adoptive profile of each. After that, we asked Ego which roles each of these people carried out in relation to the adoptee and we later clustered all these responsibilities into six categories: all/nearly all kinds of help, leisure and play, education and training, practical care, emotional support, and provision of authority. We also asked whether these nominees knew each other and how often they usually got in touch with each other.

In order to obtain some basic information about the composition and structure of their personal networks (McCarty et al., 1997) we then set a minimum threshold of five nominees. Should the network include fewer participants, that list was removed from the dataset (Kogovšek \& Ferligoj, 2005).

\subsection{Participants}

The 50 participants selected covered a wide range of ages (35-59 years old) and various marital statuses (single, married, divorced, and widowed individuals). Their distribution, however, was not at all homogeneous. Female participants clearly outnumbered males ( $86 \%$ versus $14 \%$ ), and the age range extended from $2 \%$ aged under $40,52 \%$ from 41 to 49 years of age, and $46 \%$ from 50 to 59 years of age $(M=48.24$, median $=48.5)$. In terms of marital status, it should be noted that the overwhelming majority of participants were married $(78 \%)$, while $12 \%$ were single with no stable partner, $8 \%$ were divorced, and $2 \%$ were unmarried but in a declared stable relationship. All men in the sample (7) were married at the time of our fieldwork. Forty-four percent of the parents had only one child (adopted), another $44 \%$ had two children, $12 \%$ 
were raising three children, and in only one case $(2 \%)$ were there more than three children (4) within the same family. Nearly $28 \%$ of cases included both biological and adopted children, and the age range for adoptees was two to eighteen years old. For only-child adoptees or elder adopted siblings, the mean age was 9.93 years old (median $=10$ ), while for second or middle siblings it was 9.1 (median $=9.5)$.

In order to classify the cases and to discern whether they could be combined into clusters according to plausible internal similarities, we computed a social support index which was based on the sum of all the alters nominated by Ego as providing support in a task.

This index is simply the sum of providers weighted by their proximity to Ego, according to this scale: 2 = very close (partner), 1.5 = close (close family and friends), $1=$ somewhat close, and $0.5=$ not so close. The mean was 8.84 $(\mathrm{SD}=5.85)$, and the range $0-20$. Using this index as a partition variable in the k-means cluster option of Deducer (R package), we found a three-cluster solution. These three clusters show significant inner coherence as well as clear differences between each other. The results are presented in the next section.

\section{Results}

\subsection{The main care providers and child-rearing tasks}

As we can see in Figure 1, Ego is the main care provider in most cases. That being said, we must bear in mind that most interviewees were women, and this point is highly relevant. On the one hand, gender is a major predictor of family care, given the prevalence of the gender division of labor and the major role it plays in a broader cultural sense (Butler, 1993; Yanagisako \& Delaney, 1995). On the other, and specifically concerning adoption, it plays a prominent role in nearly all the stages and different dimensions of the process (Briggs, 2012; Dorow, 2006; Rajendran et al., 2015). Shared responsibility between Ego's partner and him/herself is the second most common configuration of care provision, followed by the partner alone. These three options comprise nearly $94 \%$ of all sources, with grandparents forming an additional $3 \%$.

More specifically, Ego overwhelmingly appointed him/herself as the main provider in clothing-related matters $(82 \%)$ in every network, while his/her role is less predominant in leisure activities (48\%). It is interesting to draw attention to the certain distance between the general perception of grandparents as fundamental cornerstones in child-rearing activities (Draper, 2013; Gladstone et al., 2009; Strom \& Strom, 2000) and their actual role in our research.

\subsection{Preferred information sources and levels of concern}

In connection with this subject, we also inquired about the preferred sources of information about certain troubling issues regarding adoptive offspring that had appeared to be of particular concern to the participants during previ- 
Figure 1. Main provider according to selected caring task

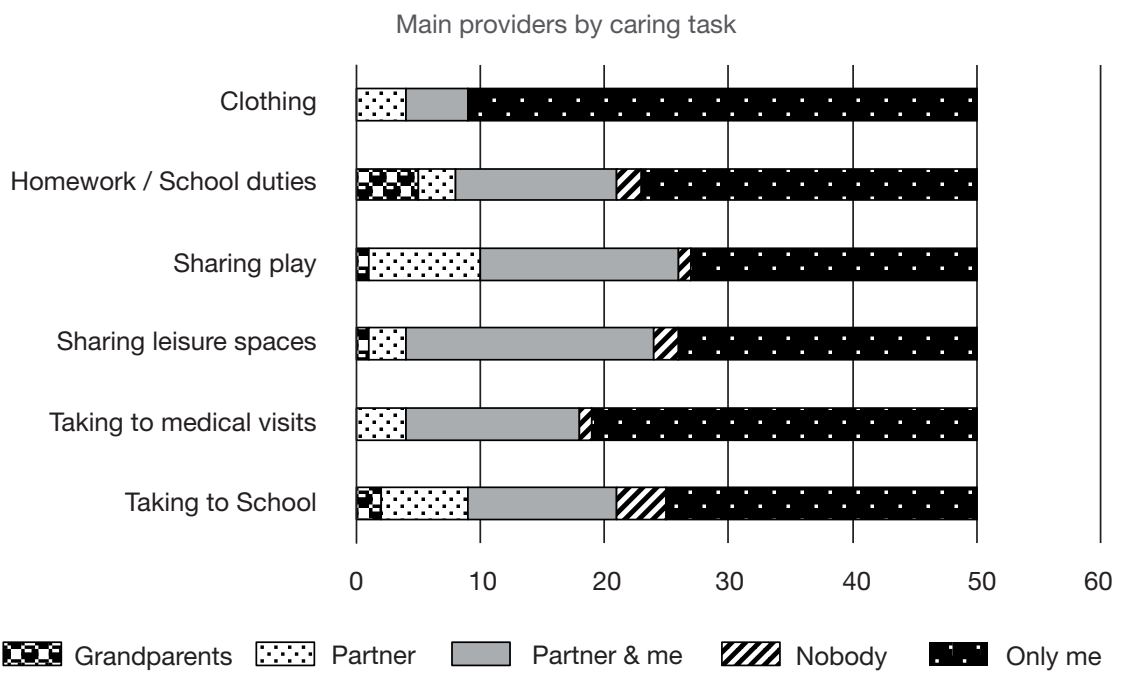

Source: Authors based on fieldwork data

ous research stages (questionnaires and in-depth interviews): education and schooling, behavior at home, social behavior, origins/roots, and aptitudes and ability. Interestingly, "Nobody" was the most frequent answer (44\% of all responses), followed by "My partner" (26\%), while "Professionals" ranked third in terms of preference (11.2\%) and "Friends" was the source preferred by $7.2 \%$ of the participants. Again, this distribution depended on the specific subject: professionals were more important sources of information for cognitive issues, whereas they were virtually irrelevant in origin debates. The dyad "My partner" and "My partner and I" were referred to frequently, especially when educational or behavioral issues were involved. This finding reinforces the emphasis given to the adoptive project as a couple-based endeavor, where the most relevant questions are addressed within this inner family core and other relatives or providers are only consulted as secondary sources of information.

Nonetheless, nearly half of the participants (47\%) expressed no serious concerns about the aforementioned issues. Only cognitive development elicited a slightly higher degree of concern, understood as a source of anxiety. In fact, all of those interviewed distinguished between general concern and anxiety, with this higher degree of concern being much less frequent in the sample and only predominant in cases where there was some serious cognitive problem with the adopted child. However, there was a certain general concern about the future. Thus, when asked about their expectations concerning problems their adopted children might face, $78 \%$ thought that the very status of the children as adoptees would cause them specific difficulties in their future lives. Among 
Table 1. K-means clusters. Main statistical data

\begin{tabular}{|c|c|c|c|}
\hline & Cluster 3 & Cluster 2 & Cluster 1 \\
\hline$n$ & 17 & 20 & 13 \\
\hline Male & 0 & 2 & 5 \\
\hline Female & 17 & 18 & 8 \\
\hline Married (\%) & 35.3 & 100 & 100 \\
\hline Age $(\bar{x})$ & 51.35 & 46.8 & 46.38 \\
\hline Biological offspring over total children (\%) & 16 & 27.02 & 18.18 \\
\hline Only children (\%) & 65 & 35 & 30.76 \\
\hline People in network $(\bar{x})$ & 7.18 & 8.3 & 10.07 \\
\hline Non-relatives in informal network (\%) & 44.26 & 33.13 & 38.16 \\
\hline$<18$ years old $(\%)$ & 11.5 & 14.5 & 13 \\
\hline 18-34 years old (\%) & 14.75 & 10.24 & 9.16 \\
\hline 35-54 years old (\%) & 33.6 & 45.18 & 50.38 \\
\hline $55+$ years old $(\%)$ & 43.44 & 30.12 & 28.24 \\
\hline Professionals (nominees) & 17 & 11 & 6 \\
\hline Non-adoptive friends in network (\%) & 42.59 & 30.9 & 32 \\
\hline Adoption as main future project & 58.82 & 30 & 23 \\
\hline Assisted reproductive technologies & 17.6 & 25 & 0 \\
\hline Density (degree mean) & 4.64 & 5.9 & 7.23 \\
\hline Support index (mean) & 2.76 & 8.85 & 16.76 \\
\hline
\end{tabular}

Source: Authors based on fieldwork data.

the most frequent reasons, phenotype-related ones were predominant (61.5\%). Far less troubling $(33.3 \%)$ was the fact of being adopted, which is considered a likely source of distress due to the dominant biologically-based folk notion of family and kinship. Interestingly, only $5.1 \%$ thought that functional diversity could become a major problem.

\subsection{The resulting clusters and networks}

In addition to gaining an overall picture of the participants, we were particularly interested in considering any factors which recur across cases, and thereby finding potential patterns of similarities that could inform future proactive interventions should any complications arise. To explore these patterns, we classified the sample into three clusters.

General data on the three clusters (Table 1) show some significant differences between the clusters. For example, Cluster 3 shows a higher rate of informal support despite the fact that $65 \%$ of its participants are unmarried. Regarding network configuration, while adoptive parents in Cluster 1 have the highest average number of nominees per network $(M=10.07)$, participants in Cluster 3 reveal themselves to be less worried about potential problems in the adoptees' future lives (70.59\%); an issue that causes greater concern in Cluster $1(92.30 \%)$. There is a significant gap between Cluster 3 (the most supportive 
networks) and Cluster 1 (the least supportive networks) in terms of concern about cognitive and physical development, with the former group displaying considerably lower levels of concern. As far as origins and general adaptation are concerned, higher levels of concern were expressed in Cluster 2 and lower levels in Cluster 1, but this group was still quite far ahead of Cluster 3.

With regard to the adoptive project, participants in Cluster 3 stood out significantly from the other clusters for having thought of adoption as a future project for a long time, regardless of the unmarried status of many participants or the fact of having had biological children first. Hence, while nearly $60 \%$ of people in Cluster 3 considered adoption a priority in their child-rearing endeavor, only $23 \%$ of the participants in Cluster 1 had made up their minds about adoption as a future parenting aspiration. Seemingly, gender distribution made no significant contribution to these differences.

As can be seen in Table 1, the support index (based on the number of support providers and the density of the informal networks) is higher in Cluster 1 and lower in Cluster 3. Nevertheless, the greater number of contacts does not equate to an increased sense of security and lower anxiety levels. Thus, the mere aggregation of contacts does not necessarily provide better child-rearing support, whereas the quality of the contacts and personal coping resources may be much more significant in this regard.

\subsection{Selection of cases}

In order to outline the most relevant features of the networks, we have selected three cases (one from each cluster) to visualize their contacts, the frequency and strength of their interconnection, and the kind of support they provide. In the resulting visualizations, obtained with specialized network representation software (EgoNet), men are represented by triangles women by circles. The node size illustrates the kind of support provided according to Ego, and ranked according to its perceived importance (the largest node $=$ all or nearly all kinds of help and then in order by decreasing size: practical care, emotional support, education/training, authority/reference, leisure and play).

\section{Case 1. Tina (Cluster 3)}

Starting in Cluster 3, our exemplary case is Tina (a pseudonym), a 52 yearold unmarried female in a "living apart together" relationship (Cross-Barnet et al., 2008; Duncan \& Phillips, 2010) with Nominee Number 2 (Figure 2). This nominee is also an adoptive mother of a 6 -year-old child. On viewing her informal support network, we can observe two clear groups. The first consists of close kin and relatives, while in the second we only find friends (who have never adopted). The link between these two groups is made by a close friend of Tina's sister (Number 2), who also has a good relationship with Ego's kin.

As is common in Cluster 3, nobody besides Ego takes on all or nearly all of the child-rearing tasks, with these being fairly distributed among the nominees. Thus, all except two friends (numbered 1 and 2) carry out practical tasks, such 
Figure 2. Tina's informal support network

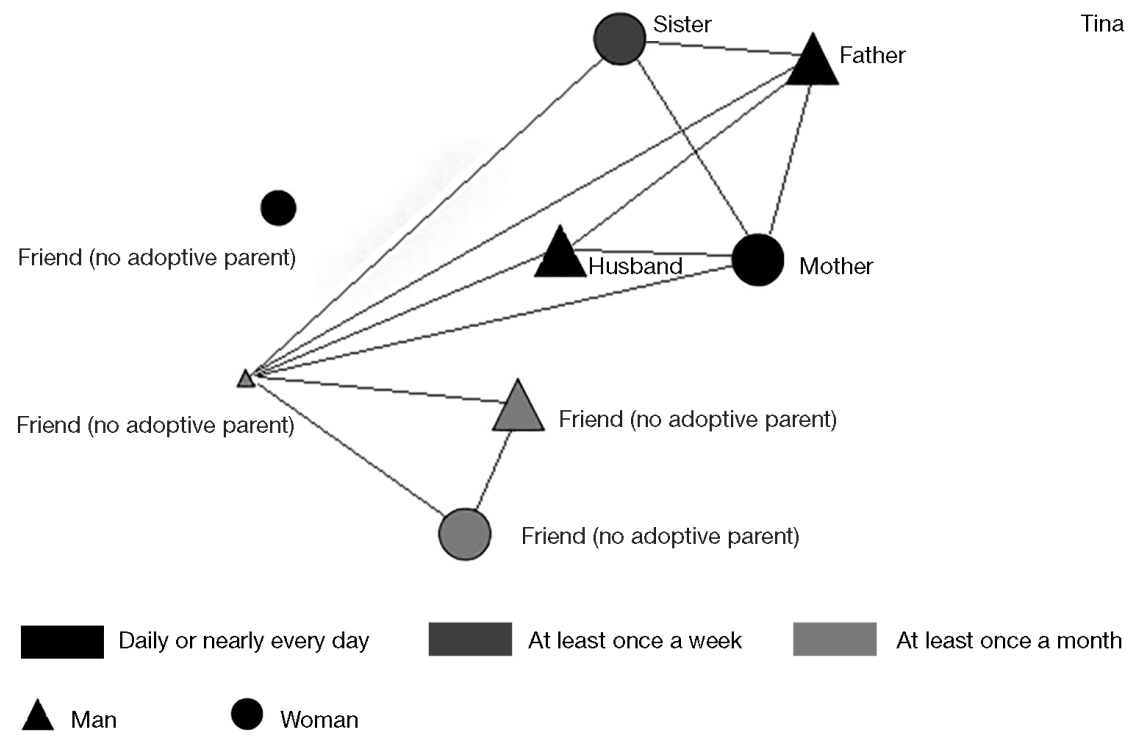

Source: Authors based on fieldwork data.

as feeding, baby-sitting, providing rides to school, and so on. Nobody was nominated as a specific provider of emotional support (advice, moral guidance, etc.) or education, as Tina is a teacher herself and takes care of all her son's needs in that respect; besides, she also gets help from her son's own teacher, who is actually a good friend of hers (Nominee Number 1). We find the same pattern with provision of authority: no specific figure is nominated for this role, but Friend 2 adopts a crucial role in leisure and play time, and this was the main reason for Tina nominating 2 as a key figure in everyday care and child-rearing activities. We have often found that our participants considered telling stories or play activities to be fundamental tasks in their child-rearing project, and thus they often nominated contacts mainly (or even solely) for that reason. Tina embodies this sort of calculated dispersion: although different contacts may be of great help as providers of moral support (namely 2, for example), their main function seems to be a different one.

\section{Case 2. Jane (Cluster 2)}

Turning to Cluster 2, we will examine the case of Jane (Figure 3). Jane is a 50-year-old married woman with two children: the eldest is a 17-year-old-boy and the youngest a 6-year-old adopted girl. As is usual in this cluster, the average number of non-family contacts in the support network is lower than in Cluster 3 and the density of the network is higher than in the previous case. Here, the multiple contacts among nominees lead to a connective entangle- 
Figure 3. Jane's informal support network

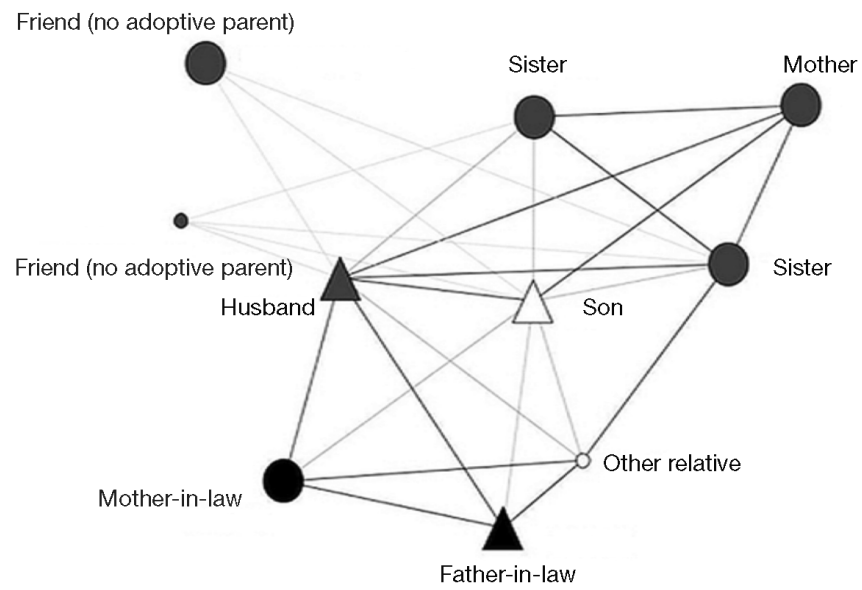

Jane

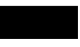

$55+$

$35-54$

$18-34$

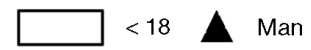

Woman

Source: Authors based on fieldwork data.

ment that reinforces the sense of internal cohesion. It is interesting to note how the older son, Jane's biological child, takes the central position in the grid.

Moreover, most of the nominees are between 35 and 54 years of age themselves - a common feature in this cluster-and women also clearly outnumber men as providers of child-rearing tasks. In terms of the frequency of contacts, there are two clear extremes: the first consists of Jane's affinal relatives (her husband and his parents), and the second revolves around Jane's own family (her husband, her eldest son, her two sisters, and her mother). Weaker ties are established between any of those providers and two non-adoptive friends (1 and 2). It is worth noting that nobody in the network provides all_or nearly all-kinds of help, not even Jane's husband, while she appointed up to six nominees as fundamental providers of practical care: her husband and in-laws on the one hand, and her sisters and mother on the other. Again, nobody is expressly designated as a pillar of emotional support although, according to Ego, all of them are of great help in this sense at some level. In particular, Jane's father in-law is labelled as "'grandfather', so he does what a grandfather normally does" (Jane). This sort of answer is rather common among participants, revealing the weight of ideologically-based roles among kin and family, mainly concerning the role of grandparents, even in cases where they do not replace the adoptee's absent parents (Hayslip \& Kaminski, 2005; Neil, 2007a; Pinson-Millburn et al., 1996).

Whereas education and training roles are frequently taken on by the eldest son and by Nominee Number 1 (because of her own professional expertise), nobody was specifically appointed as the main figure of authority over the 
child. Despite this apparent absence, Jane stated that her daughter's eldest brother had a strong influence on her in matters of schooling and education, thus becoming a sort of role model for the daughter. By the same token, peers are very important in the adoptee's leisure time and in this case, the most fundamental piece of the network is the child's best friend, who is the same age as her and with whom she shares most activities. At a different level, Friend 2 was appointed as a go-to figure for her in her spare time.

\section{Case 3. Peter (Cluster 1)}

Lastly, our illustrative case from Cluster 1 is Peter (Figure 4), a 46-year-old married male with two adopted children (both girls). As is characteristic of this group, he was found to have larger networks which are strongly weighted toward contacts between 35 and 54 years of age. Again, there are two clearlydefined sections: the first consists of Peter's affinal relatives and other family members connected to them and the second includes his family of orientation plus one brother's spouse; the connector between both networks being Peter's wife. The strongest relationships take place between close kin, and the connections between these two discrete sections are rather occasional. According to Ego, the only person who takes care of all or nearly all child-rearing tasks is his spouse, in contrast to that observed when Ego's gender is the opposite. Gender also plays an important role in practical care, since only women are appointed as fundamental providers, all from the affinal side (wife's mother, sister, and sister-in-law). Conversely, only men are appointed as leisure and play sources: one boy who is the same age as Peter's adopted children (10 years old) and

Figure 4. Peter's informal support network
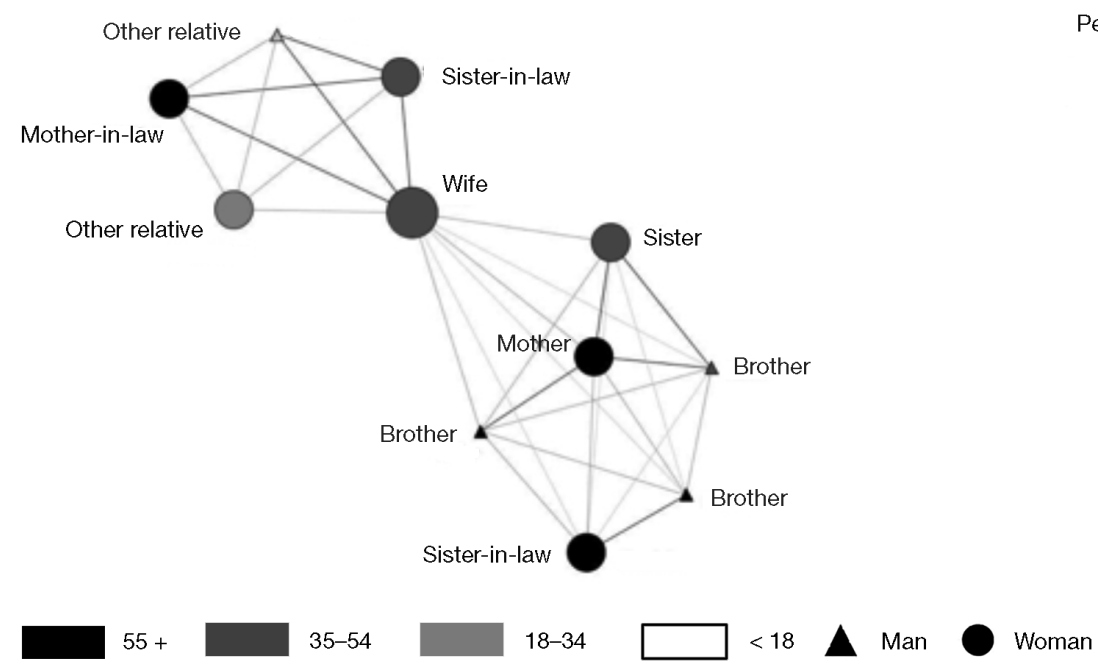

Source: Authors based on fieldwork data. 
his two brothers. Nobody is mentioned either as a fundamental emotional source or as an educational pillar. This last issue is easily handled within the couple, since both are teachers. Again, there is no specific authority figure or role model.

\section{Discussion}

According to our sample, informal support networks in international adoption rely more on women than on men and, interestingly, more on non-adoptive friends $(67.5 \%)$ than on adoptive ones $(32.5 \%)$. This finding is coherent with the statements of McKay \& Ross (2010) and McKay et al. (2010) on the importance of sources of support for adoptive parents, though it shows the relevance of non-adoption-related sources in everyday care when no specific stressors are present. Ego's own parents have a more noticeable weight than his/ her parents-in-law $(67.5 \%$ versus $32.5 \%)$, but in both cases there is a defined gender imbalance, with mothers $(63 \%)$ and mothers-in-law $(69.2 \%)$ being much more present than fathers $(37 \%)$ and fathers-in-law (30.8\%). This trend is maintained even when Ego is a man, though in our sample they are markedly in the minority. Nearly $60 \%$ of all nominees are close kin or relatives to some degree. Friends make up $19 \%$ and professional caregivers $8 \%$, while $11.6 \%$ are labelled as "others" and range from religious counselors to older peers in boy scout-like associations.

Concerning the type of help provided, tasks related to practical care are by far the most frequent among nominees $(37.7 \%)$ and provision of authority is the least cited (1.6\%). Looking at results by cluster, it is especially significant that emotional support and influence over the adopted child is mentioned in only four cases for a total of six nominees (20.7) in Cluster 3, while in Cluster 2 we found seven cases and 12 nominees (44.4\%) and in Cluster 1, five cases and 11 nominees (40.7\%). If we take a close look at the difference between clusters, the variable proportion of professional caregivers is noticeable: $50 \%$ of such roles are nominees in Cluster 3, 32\% in Cluster 2 and 18\% in Cluster 1.

In our view, the most crucial difference among clusters relates to Ego's primary adoptive project. While $38 \%$ of all interviewees considered adoption as being their first and foremost parental endeavor (i.e., they had decided to adopt even before trying to have biological children), the affirmative responses to this question in Cluster 3 clearly outnumbered those in the other two groups (53\% of the total versus $31.6 \%$ in Cluster 2 and $15.8 \%$ in Cluster 1). Another significant distinction concerns assisted reproductive treatment (ART): whereas $37.5 \%$ of all interviewees have made use of such reproductive assistance, there is a noticeable variance between clusters $(62.5 \%$ of this group were in Cluster 2 , while nobody had tried these treatments in Cluster 1). This means that in Cluster 1 less than 18\% of participants had tried ART, while in Cluster 2 no less than a quarter had done so. If we combine these data with the degree and types of concerns of our participants, we find an apparent contradiction: those who have smaller networks and are mostly single female-headed families 
feel more confident in the adoption process and feel less unease about their children's development and adaptation. The reason, according to our data, can be found in the quality of the adoption project, which started much earlier and developed as a primary goal in itself, while in other clusters international adoption appears more as a vicarious procreation strategy.

Finally, it is worth mentioning that when asked about fundamental childrearing duties, without providing the researchers with a closed inventory of specific tasks, five different (though complementary) fields emerged: (1) provision of authority and acting as a behavioral role model for the child; (2) emotional support for both the adoptive parent(s) and for the child, but especially for the latter in the context of our research; (3) practical care tasks that range from taking children to and from school to feeding or housing them; (4) educational activities, which include helping minors with their homework to solving specific doubts about their education; and (5) leisure time and play activities, which obviously vary according to age. The latter is a particularly highly valued activity for many participants, and one that explains the inclusion of children's peers (often minors themselves) as fundamental nominees in the informal networks. Certain nominees were sometimes referred to as a sort of overall provider who cope with different duties at nearly all levels, if not all of them. Frequently, these nominees are close kin or relatives, but friends may occasionally be included in this category as well. The key factor in our sample was the emotional closeness between the referral parent and the nominee, no matter how experienced the latter may be in adoption matters.

\section{Conclusion and limitations}

In this research, we have examined the usual everyday assistance that adoptive parents may regularly count on, taking into account the connections among child-rearing agents and the quality of relationships in the domain of adoptive care. One key finding of our research is that larger networks do not necessarily imply better support or significant alleviation of anxiety about the present and future of adopted children. In fact, adoptive parents who have made up their minds about adoption as a primary procreative goal are the least anxious about their children's adaptation and future. It is the adoptive project that really matters. In addition, adoptive projects have revealed themselves to be firmly structured around a close circle of support: mainly the partner, close kin, and relatives, although in this scenario it is very important to have the support of friends (not necessarily adoptive parents themselves, who were a minority in our participants' networks). In addition, we have shown how children can play a role in these support networks, especially in the domain of play.

Apart from these novel insights, our data confirm the findings of previous studies, namely that support received from informal networks is the most helpful for adoptive parents; a factor which underlines the importance of the family's own informal support network (Kramer \& Houston, 1998). Our results 
also support the theses of McGrath et al. (2014) that the perception of social support may be even more relevant than the actual support received especially when it comes to provision of authority and emotional support, although that influence does not always come from paternal/maternal figures or even from adult individuals. In this light, siblings often become a mainstay resource for post-adoption families, regardless of their non-adult status.

We are well aware of the limitations of our study. First of all, the high percentage of female participants shows a gender disparity that should be counterbalanced in future studies on informal networks in IA. Secondly, network analysis can be extended to online social networking and other sources of virtual connections with potential providers. Consequently, a simultaneous exploration of online and offline relationality would be advisable. Finally, a less adultcentric view of care and support could be provided in the future by including children's views (at least older children's viewpoints) about the child-rearing process.

\section{Implications for policymaking and professional practice}

In comparison with formal welfare networks, informal support may follow a less structured pattern and therefore seem a highly individual matter. In addition, a large body of literature shows how stressful environments due to health or psychological problems do appear to be primary network activators, because of the need for assistance at emotional or practical levels. Most professional practice addresses these high-risk situations based on the premise that the larger and the more specialized the network, the better it is for securing the requested help. However, our study shows that in ordinary situations, informal networks do not need to be that big to be effective and that they are highly strategic in nature. In fact, we found that people with smaller networks expressed less anxiety over current or future problems.

Hence, as we have seen in our case examples, the density of the network may not be in direct correlation with the effectiveness of such a grid. It is essential to consider the quality of the contacts if we are to understand why size does not necessarily matter in this case. Unfortunately, in problematic cases there is a considerable lack of knowledge about the network configuration before and after the assistance is needed. Therefore, we largely ignore how those networks changed and what the nature of those changes were. Our findings concerning the composition of informal networks confirm Lansford et al. (2001)'s call to scrutinize the links between family processes and structures. Furthermore, future research should explore how such bonds crisscross with the use of formal networks and other strategies that strengthen family resilience (Henry et al., 2015).

In addition, as other research has found (Grau Rebollo et al., 2016), the demand for information follows informal pathways in parallel to the demand for professional advice. Accordingly, when formal sources are called upon, the influence of informal contacts may not only remain intact but could even 
be intensified. As we show in this paper, those informal resources largely consist of other family members, non-kin, and friends without adopted children; that is, people who may not have direct knowledge about adoption. The potential relevance of this parallel informal channel should be taken into account in future studies to better inform precise guidance for practitioners and policymakers.

\section{Bibliographic references}

BidART, Claire and Lavenu, Daniel (2005). "Evolutions of Personal Networks and Life Events”. Social Networks, 27 (4), 359-376. $<$ https://doi.org/10.1016/j.socnet.2004.11.003>.

BrigGS, Laura (2012). "Feminism and Transnational Adoption: Poverty, Precarity, and the Politics of Raising (Other People's?) Children". Feminist Theory, 13 (1), $81-100$. $<$ https://doi.org/10.1177/1464700111430177>.

Bryan, Valery, Flaherty, Chris and Saunders, Carrie (2010). "Supporting Adoptive Families: Participant Perceptions of a Statewide Peer Mentoring and Support Program". Journal of Public Child Welfare, 4 (1), 91-112. <https://doi.org/10.1080/15548730903563178>.

BuTLER, Judith (1993). Bodies That Matter: On the Discourse Limits of "Sex". New York \& London: Routlege.

Claridge, Amy (2014). "Supporting Birth Parents in Adoption: A Couple Treatment Approach". Adoption Quarterly, 17 (2), 112-133. <https://doi.org/10.1080/10926755.2014.891545>.

Cross-Barnet, Caitlin, Cherlin, Andrew and Burton, Linda (2008). Cohabiting on the Edge: Living Together Apart. Baltimore, MD.

CuTrona, Carolyn (2000). "Social Support Principles for Strengthening Families: Messages From America”. In: Canavan, Jon; Dolan, Pat and PinKerTon, John (eds.). Family Support: Direction from Diversity. London: Jessica Kingsley Publishing.

Denuwelaere, Mieke and Bracke, Piet (2007). "Support and Conflict in the Foster Family and Children's Well-Being: A Comparison Between Foster and Birth Children". Family Relations, 56 (1), 67-79. <https://doi.org/10.1111/j.1741-3729.2007.00440.x>.

Dorow, Sara (2006). Transnational Adoption: A Cultural Economy of Race, Gender, And Kinship. New York: New York University Press.

Draper, Heather (2013). "Grandparents' Entitlements snd Obligations". Bioethics, 27 (6), 309-316. $<$ https://doi.org/10.1111/bioe.12028>.

DunCA, Simon and Phillips, Miranda (2010). "People Who Live Apart Together (Lats) - How Different Are They?". The Sociological Review, 58 (1), 112-134. <https://doi.org/10.1111/j.1467-954x.2009.01874.x>.

Erich, Stephen, Leung, Patrick, Kindle, Peter and Carter, Sharon (2005). "Gay and Lesbian Adoptive Families: An Exploratory Study of Family Functioning, Adoptive Child's Behavior, and Familial Support Networks". Journal of Family Social Work, 9 (1), 17-32. <https://doi.org/10.1300/j039v09n01_02>. 
Gladstone, James, Brown, Ralph, and Fitzgerald, Kerri-Ann (2009). “Grandparents Raising Their Grandchildren: Tensions, Service Needs and Involvement with Child Welfare Agencies". International Journal of Aging and Human Development, 69 (1), 55-78 <http://doi.org/10.2190/AG.69.1.d>.

GoldBerG, Abbie, and Smith, Julianna (2008). "Social Support and Psychological Well-Being in Lesbian and Heterosexual Preadoptive Couples". Family Relations, 57 (3), 281-294. <https://doi.org/10.1111/j.1741-3729.2008.00500.x>.

Grau Rebollo, Jorge (2011). "Kinship, Adscription and Child Rearing: Cultural Constructions of International Adoption and Circulation of Children". Revista de antropología social, 20, 31-54. <https://dx.doi.org/10.5209/rev_RASO.2011.v20.36261>.

Grau Rebollo, Jorge, García Tugas, Lourdes and Vich Bertrán, Júlia (2016). "Flujos de información e interacciones online en el marco de la crianza adoptiva". E-Quaderns, 21 (2), 38-59.

Grau Rebollo, Jorge, Vich, Júlia and García, Lourdes (2014). "Redes de crianza, cuidados y roles parentales en el ámbito de la adopción internacional”. In: PIELLA, Anna, Uribe, José María and Jociles, María Isabel (eds.). Parentalidades múltiples y articulaciones disciplinarias. De fronteras, encrucijadas y vinculos. Tarragona: Universitat Rovira i Virgili.

GrozA, Victor (1996). Successful Adoptive Families: A Longitudinal Study of Special Needs Adoption. Westport, Connecticut: Praeger.

Hayslip, Bert and KaminSKI, Patricia (2005). "Grandparents Raising Their Grandchildren: A Review of the Literature and Suggestions for Practice". The Gerontologist, 45 (2), 262-269. $<$ https://doi.org/10.1093/geront/45.2.262>.

Henry, Carolyn, Sheffield Morris, Amanda. and Harrist, Amanda (2015). "Family Resilience: Moving into the Third Wave". Family Relations, 64 (1), $22-43$. <http://doi.org/10.1111/fare.12106>.

Hoffman, Katie (2014). "Beyond a Two-Tier Service? Agency and Parent Experiences, Expectations, and Perspectives of Support in Intercountry Adoption in the United Kingdom”. Adoption Quarterly, 17 (3), 227-246. $<$ http://doi.org/10.1080/10926755.2014.891548>.

Howell, Signe (2006). The Kinning Oof Foreigners: Transnational Adoption in a Global Perspective. London: Berghahn Books.

Howell, Signe and Melhuus, Marit (2009). "Race, Biology and Culture in Contemporary Norway: Identity and Belonging in Adoption, Donor Gametes and Immigration". In: WADE, Peter (ed.). Race, Ethnicity and Nation. Perspectives from Kinship and Genetics. Oxford, New York: Berghahn Books.

Kramer, Laurie and Houston, Doris (1998). "Supporting Families as They Adopt Children with Special Needs”. Family Relations, 47 (4), 423-432. $<$ https://doi.org/10.2307/585273>.

LANSFord, Jennifer, Ceballo, Rosario, AbBey, Antonia and Stewart, Abigail (2001). "Does Family Structure Matter? A Comparison of Adoptive, Two-Parent Biological, Single-Mother, Stepfather, and Stepmother Households". Journal of Marriage and Family, 63 (3), 840-851. <https://doi.org/10.1111/j.1741-3737.2001.00840.x>. 
McCarty, Christopher, Bernard, Russell, Killworth, Peter, Shelley, Gene and JoHnsen, Eugene (1997). "Eliciting Representative Samples of Personal Networks". Social Networks, 19 (4), 303-323.

<http://doi.org/10.1016/S0378-8733(96)00302-4>

MCCARTY, Christopher and MOLINA, José Luis (2014). "Social Network Analysis". In: BERnARD, Russell and GravleE, Clarence (eds.). Handbook of Methods in Cultural Anthropology. Lanham: Rowman \& Littlefield.

Mcgrath, Brian, Brennan, Mark, Dolan, Peter and BarnetT, Rosemary (2014). "Adolescents and Their Networks of Social Support: Real Connections in Real Lives?" Child and Family Social Work, 19 (2), 237-248. <http://doi.org/10.1111/j.1365-2206.2012.00899.x>.

MCKaY, Katherine and Ross, Lori (2010). "The Transition to Adoptive Parenthood: A Pilot Study of Parents Adopting in Ontario, Canada". Children and Youth Services Review, 32 (4), 604-610. <https://doi.org/10.1016/j.childyouth.2009.12.007>.

McKay, Katherine, Ross, Lori and GoldberG, Abbie (2010). "Adaptation to Parenthood during the Post-Adoption Period: A Review of the Literature". Adoption Quarterly, 13 (2), 125-144. $<$ https://doi.org/10.1080/10926755.2010.481040>.

Miall, Charlene and MARCH, Karen (2005). "Open Adoption as a Family Form: Community Assessments and Social Support”. Journal of Family Issues, 26 (3), 380-410. $<$ https://doi.org/10.1177/0192513x04270210>.

NeIL, Elsbeth (2007a). "Coming to Terms with the Loss of a Child: The Feelings of Birth Parents and Grandparents about Adoption and Post-Adoption Contact". Adoption Quarterly, 10 (1), 1-23. $<$ https://doi.org/10.1300/j145v10n01_01>.

- (2007b). "Supporting Post-Adoption Contact for Children Adopted from Care: A Study of Social Workers' Attitudes”. Adoption Quarterly, 10 (3-4), 3-28. <https://doi.org/10.1080/10926750802163170>.

Palacios, Jesús and BrodZinsky, David (2010). "Review: Adoption Research Trends, Topics, Outcomes". International Journal of Behavioral Development, 34 (3), 270-284. <https://doi.org/10.1177/0165025410362837>.

Pinson-Millburn, Nancy (1996). "Grandparents Raising Grandchildren”. Journal of Counseling o Development, 74 (6), 548-554. <https://doi.org/10.1002/j.1556-6676.1996.tb02291.x>.

PudrovsKA, Tetyana (2008). "Psychological Implications of Motherhood and Fatherhood in Midlife: Evidence from Sibling Models". Journal of Marriage and Family, 70 (1), 168-181. <http://doi.org/10.1111/j.1741-3737.2007.00469.x>.

Rajendran, Khushmand, Smith, Brenda and VideKa, Lynn (2015). “Association of Caregiver Social Support with the Safety, Permanency, and Well-Being of Children in Child Welfare". Children and Youth Services Review, 48, 150-158. $<$ http://doi.org/10.1016/j.childyouth.2014.12.012>.

SeligmanN, Linda (2006). "Cross-Cultural Approaches to Adoption/Cultures of Transnational Adoption”. American Anthropologist, 108 (3), 544-547. $<$ https://doi.org/10.1525/aa.2006.108.3.544>.

STROM, Robert and STrom, Shirley (2000). "Meeting the Challenge of Raising Grandchildren". International Journal of Aging and Human Development, 51 (3), 183-198. $<$ https://doi.org/10.2190/fr92-egw2-vevu-p8cr>. 
Wellman, Barry (2007). The Network Is Personal: Introduction to a Special Issue of Social Networks. Social Networks, 29 (3), 349-356. <http://doi.org/10.1016/j.socnet.2007.01.006>.

Wellman, Barry and Wortley, Scot (1990). "Different Strokes from Different Folks: Community Ties and Social Support”. American Journal of Sociology, 96 (3), 558-588. <https://doi.org/10.1086/229572>.

YANAGISAKO, Sylvia and Delaney, Carol (eds.) (1995). Naturalizing Power: Essays in Feminist Cultural Analysis. New York: Routledge. 
